\title{
Characterization of the erythropoietin/erythropoietin receptor axis in a rat model of liver damage and cholangiocarcinoma development
}

\author{
Federico Moriconi • Pierluigi Ramadori • Frank C. Schultze • \\ Martina Blaschke $\cdot$ Ahmad Amanzada $\cdot$ Sajjad Khan • \\ Giuliano Ramadori
}

Accepted: 10 September 2012/ Published online: 4 October 2012

(C) The Author(s) 2012. This article is published with open access at Springerlink.com

\begin{abstract}
It has been recently shown that the biological effects of erythropoietin (EPO) are not limited to the hematopoietic compartment but, as pleiotropic glycoprotein, this hormone can exert pro-angiogenic and tissue-protective functions also in a wide range of non-hematopoietic organs. The role of EPO and the effective functionality of its receptor in solid tumors are still a controversial point of debate. In the present work we analyzed the gene expression of EPO and its cognate receptor (EpoR) in a rat model of thioacetamideinduced damage and tumor. An analysis of the EPO/EpoR axis was also performed on human cholangiocarcinoma (CC) cell lines. A progressive increase of EPO and EpoR mRNA can already be observed during the fibrotic-cirrhotic development with a peak of expression rising at tumor formation (24.7 \pm 9.9 -fold increase and $15.5 \pm 1.1$-fold increase, respectively, for the two genes). Co-localization studies by immunofluorescence revealed hepatocytes in the regenerative cirrhotic nodules (Hep Par- $1^{+}$) and in the dysplastic bile duct cells $\left(\mathrm{CK} 19^{+}\right)$as the major EPO producers
\end{abstract}

F. Moriconi and P. Ramadori contributed equally to the work.

Electronic supplementary material The online version of this article (doi:10.1007/s00418-012-1037-x) contains supplementary material, which is available to authorized users.

F. Moriconi $(\bowtie) \cdot$ F. C. Schultze $\cdot$ M. Blaschke .

A. Amanzada - S. Khan - G. Ramadori

Department of Gastroenterology and Endocrinology,

Center of Internal Medicine, University of Göttingen,

Robert Koch Straße 40, 37075 Göttingen, Germany

e-mail: fmoriconi@med.uni-goettingen.de

P. Ramadori

Department of Cell Physiology and Metabolism,

University Medical Centre of Geneva, Geneva, Switzerland in this specific condition. The same cell populations, together with endothelial cells, exhibited an increased expression of EpoR, although all the non-parenchymal cell populations in the liver exhibited modest basal mRNA levels. Challenging human CC cells, Mz-Cha-2, with a combination of EPO and $\mathrm{SCF}$ resulted in a synergistic effect on the gene expression of EPO, CyclinD1 and PCNA. This study suggests that the autocrine and paracrine release of endogenous EPO in the microenvironment may contribute to the development and maintenance of the CC possibly in cooperation with other signaling pathways.

Keywords Cholangiocarcinoma (CC) .

Chronic liver injury · Erythropoietin (EPO) .

Erythropoietin receptor (EpoR) - Thioacetamide (TAA)

\section{Introduction}

The biological effects of erythropoietin (EPO) are not only limited to the hematopoietic system, but also an increasing body of evidences has recently focused attention on a wide spectrum of functions in several non-hematopoietic organs (reviewed in Lombardero et al. 2011). Indeed, the presence of EPO and its cognate receptor (EpoR) has been documented in many non-hematopoietic cell types, such as vascular endothelial cells, smooth muscle cells, cardiac myocytes, neurons and macrophages (Brines and Cerami 2012). In addition to stimulating erythropoiesis, EPO has been reported to promote angiogenesis, vascular stability and endothelial cell survival (Ribatti et al. 2003). EPO has also been suspected of procancerogenic activity.

It has been postulated that, if tumor cells express EpoR, erythropoiesis-stimulating agents could activate these receptors to induce tumor cell proliferation (Hadland and 
Longmore 2009). Moreover, several cancer cells, such as breast carcinoma, endometrial carcinoma and lung carcinoma cells (Hedley et al. 2011), have been described as being able to synthesize EPO and to express the EpoR on their surface suggesting a possible autocrine or paracrine effect of the hormone on cell survival and proliferation. However, the functional role of EPO in tumor biology is still far from being fully understood. In spite of a growing amount of in vitro and in vivo studies (Shi et al. 2010; Kumar et al. 2011) that associate the presence of EpoR with the promotion of cancer cells proliferation and invasion, a linear correlation between EpoR activation and an efficient responsiveness to exogenous EPO administration has not been established.

At the bedside, the therapeutic benefit of the clinical use of erythropoiesis-stimulating agents in cancer is still a delicate controversial discussion point. Indeed, cancerrelated and chemotherapy-induced anemia that represents a further negative variable in the quality of life for many cancer patients prompted clinicians to use EPO and EPO derivatives in several clinical trials (McKinney and Arcasoy 2011). Although in certain conditions it was effective in correcting the hematocrit and hemoglobin levels, detrimental effects on tumor progression and increased mortality have been reported in a considerable number of clinical studies (Szenajch et al. 2010).

Previous clinical reports have recorded erythrocytosis and an increase in EPO serum levels in patients with hepatocellular carcinoma (Cheng et al. 2002), whereas histological evidences of augmented EPO synthesis have been identified from the analysis of hepatic cancer samples and liver tissue surrounding the tumor (Ribatti et al. 2007). So far, the EPO/EpoR system has been indicated as playing a major angiogenetic role in murine models of hepatocarcinogenesis (Nakamatsu et al. 2004) and in vitro studies have indicated the presence of mRNA and protein of both genes in HepG2 and Hep3B hepatoma cell lines. However, no effect on cell proliferation or invasion has been observed after exogenous EPO administration (Farrell and Lee 2004).

Cholangiocarcinomas (CC) refer to malignancies of the biliary tree epithelia. They are relatively rare cancers (about $3 \%$ of malignant tumors) in western countries (USA and Europe), but remain difficult to diagnose and treat, respond very poorly to chemotherapy and radio-therapy and have a high mortality rate: over $50 \%$ in untreated patients within a few months of diagnosis (Patel 2011).

The present study offers a further insight into the tumor biology of the EPO/EpoR axis, with a particular focus on chronic liver injury and its progression to $\mathrm{CC}$. With the current experimental model, we not only analyzed the progressive changes in EPO gene expression and protein production during chronic liver damage and tumor development, but also attempted to identify the cellular sources and the probable targets of the hematopoietic hormone.
Finally, we pursued the characterization of functional effects of EPO on proliferation and growth of human CC cell lines, also in combination with the hematopoietic growth factor SCF that has been previously identified in the same cell populations together with its receptor c-kit. A possible synergistic effect on genes involved in cell cycle regulation interestingly emerged by challenging $\mathrm{CC}$ cell lines with a combination of growth factors.

The aberrant expression of EPO and EpoR described in this rat model of $\mathrm{CC}$ and confirmed in human cell lines suggests a possible local autocrine and paracrine release of the hormone not only for direct tumor survival and proliferation, but also for the hepatocytes' response to chronic liver damage, possibly in a synergistic regulatory mechanism with other growth factors.

\section{Materials and methods}

Animals and experimental model

Male Sprague-Dawley (SD) rats weighing 330-370 g were used in these experiments. The animals were obtained from Charles River (Sulzfeld, Germany) and Harlan Winkelmann (Borchen, Germany) and received human care according to the guidelines of the local institution and the National Institutes of Health. We adhered to the institutional policies and the relevant guidelines for care and use of laboratory animals. All animal experiments were approved by the ethics review board, and were continuously supervised by the local ethic commission. The animals were divided into five groups, including a control group for each time point and experimental groups following a time progression up to 18 weeks. Rats were housed in an animal room with a 12:12$\mathrm{h}$ light-dark cycle, with food and water available ad libitum. $\mathrm{CC}$ was induced according to the protocol of Yeh et al. (2004) with a slight modification. The experiment group received $500 \mathrm{mg} / \mathrm{l}$ thioacetamide (TAA) (Sigma Aldrich) in their drinking water every day up to the time they were killed. Four control and five TAA-treated rats were killed every fourth week during the study to examine the effect of TAA. As $80 \%$ of TAA-treated rats developed CC at week 16 , the experiment was stopped at week 18 , at which time $100 \%$ of the TAA-treated rats had developed CC.

Immunohistochemical analysis

Five micrometer cryostat sections were evaluated by immunohistochemistry (Reichert Jung, Wetzlar, Germany) with rabbit anti-EPO and rabbit anti-EpoR (Santa Cruz Biotech), mouse anti-Hep Par-1 (Dako), mouse anti-CK19 (Novocastra), mouse anti-ED-2 (Serotec) and mouse antialpha-SMA antibodies (Sigma). Cryostat sections were air 
dried and used for immunohistochemical studies after fixation for $10 \mathrm{~min}$ in acetone at room temperature. After blocking of non-specific binding with $1 \%$ bovine serum albumin (Serva, Heidelberg, Germany) and $10 \%$ goat serum (DAKO, Glostrup, Denmark) containing PBS (Biochrom, Berlin, Germany) for $1 \mathrm{~h}$ at room temperature, the sections were incubated overnight at $4{ }^{\circ} \mathrm{C}$ with a single or two primary antibodies simultaneously. Antigens were visualized using two different immunohistochemical methods. For light microscopy, the standard alkaline phosphatase anti-alkaline phosphatase (APAAP)/Fast Red method was used as described previously (Neubauer et al. 2008). Double immunostaining for studies of antigen colocalization was performed using fluorescent conjugates. The rabbit polyclonal and mouse monoclonal antibodies were detected with Alexa-555-conjugated goat-anti-rabbit and Alexa-488 conjugated goat-anti-mouse secondary antibodies (Molecular Probes, Leiden, Netherlands). Sections were counter-stained with DAPI (Molecular Probes) and observed with an epifluorescence microscope (Axiovert 200 M, Zeiss, Jena, Germany). Negative control immunostainings were performed by omitting the primary antibody and using isotype-matching control immunoglobulins.

Total protein isolation and Western blot analysis

Liver tissue samples frozen in liquid nitrogen at several time points were lysed in lysis buffer $(0.50 \mathrm{M}$ Tris $\mathrm{HCl} \mathrm{pH} \mathrm{7.6,}$ $150 \mathrm{mM} \mathrm{NaCl}, 10 \mathrm{mM}$ EDTA, $1 \%$ Triton X-100, $1 \mathrm{mM}$ PMSF and $10 \mu \mathrm{l} / \mathrm{ml}$ cocktail proteases inhibitors) and incubated for $30 \mathrm{~min}$ on ice. After $15 \mathrm{~min}$ of centrifugation at $12,000 \mathrm{rpm}$, the protein concentration in the supernatant was determined with the Coomassie method (Pierce, Rockford, IL). $50 \mu \mathrm{g}$ of total protein-containing samples was loaded on a 4-12\% NUpage Bis-Tris gel (Invitrogen) and separated by electrophoresis followed by protein transfer onto a nitrocellulose membrane according to the manufacturer's instructions. Immunodetection was performed according to the ECL-Western blotting protocol. The primary antibodies mouse anti-EPO (Acris Antibodies), rabbit anti-EpoR (Santa Cruz Biotech; M20) and mouse anti-EpoR (clone 3D10, Sigma) were used in a 1:200 dilution. Beta-actin, and peroxidase-labeled anti-mouse and anti-rabbit secondary antibodies were each used in a 1:1,000 dilution.

Isolation of different liver cell populations from adult control rats and culture conditions

Hepatocytes were isolated from healthy adult rats by means of collagenase treatment in a recirculating in situ perfusion technique and cultured as reported previously (Ramadori et al. 2010a). Hepatic stellate cells (HSC) and myofibroblasts were isolated by sequential in situ perfusion with collagenase and pronase (Piscaglia et al. 2009). After perfusion with collagenase, hepatocytes were removed by low-speed centrifugation. Non-parenchymal cells were separated from cellular debris and erythrocytes by density centrifugation in a Nycodenz gradient. Sinusoidal endothelial cells (SECs) and Kupffer cells were obtained as reported earlier (Armbrust et al. 2004).

Culture and stimulation of human CC cell lines

Mz-Cha-2 and EGI-1 were cultured in a DMEM medium, whereas TFK-1 CC cells were cultured in an RPMI medium as reported previously. Cells were starved overnight by serum depletion before stimulation analyses. SCF and EPO recombinant human proteins were used at a concentration of $10 \mathrm{ng} / \mathrm{ml}$ and $10 \mathrm{U} / \mathrm{ml}$, respectively, alone or in combination for $24 \mathrm{~h}$. After stimulation with growth factors, the cells were harvested for protein and RNA preparation. In the control groupm, cells were harvested at the same time point without adding growth factors. At 24 and 48 h, a dose-response curve was obtained for EPO treatment at concentrations of $0.1,1$ and $10 \mathrm{U} / \mathrm{ml}$.

RNA isolation and real-time PCR analysis

RNA was isolated from the rat livers and the isolated cell populations as described previously (Ramadori et al. 2010b). Reverse transcription of RNA into cDNA was performed with the Superscript ${ }^{\circledR}$ kit (Invitrogen), according to the manufacturer's instructions. Real-time PCR analysis of cDNA was performed with an Applied Biosystems Step One Plus ${ }^{\circledR}$ Sequence detection system using Fast Taq Sybr Green ${ }^{\circledR}$ (AB, Applied Biosystems) and the primers used are listed in Table 1. The primers were synthesised by Invitrogen. The quantity of the PCR products of the genes of interest $(Q)$ was normalized to the housekeeping gene. Fold change expression was calculated using the threshold PCR cycle values of the housekeeping gene Ubiquitin $\mathrm{C}(\mathrm{UBC})\left(\mathrm{Ct}_{\mathrm{UBC}}\right)$, using the formula: $Q=2^{-\Delta \mathrm{Ct}}$, where $\Delta \mathrm{Ct}=\mathrm{Ct}_{\text {target }}-$ $\mathrm{Ct}_{\mathrm{UBC}}$, and $\beta$-actin for rat samples, whereas $\beta$-actin and GADPH for human samples. The quantities of normalized PCR products detected in the livers of treated rats were compared to the values in control rats, and the relative expression was plotted against the observation time. In all cases, two or three series were analyzed in duplicate.

\section{Statistics}

Descriptive statistics, $t$ test, and two-way ANOVA for dependent and independent samples and graphs were performed with Statistica 6.0 (StatSoft, Hamburg, Germany). We used a constant level of $P=0.05$ for rejection of the null hypothesis. 
Table 1 Real-time RT-PCR primers used in the study

\begin{tabular}{lll}
\hline Name & Forward & Reverse \\
\hline rno EPO & CCA GCC ACC AGA GAG TCT TC & TGC AGA AAG TAT CCG CTG TG \\
rno EpoR & ACA CGT CGA GTT TTG TGC CA & TGG ATG ATG CGG TGG TAG C \\
rno $\beta$-actin & TGT CAC CAA CTG GGA CGA TA & AAC ACA GCC TGG ATG GCT AC \\
rno UBC & CAC CAA GAA CGT CAA ACA GGA A & AAG ACA CCT CCC CAT CAA ACC \\
hs EPO & CTC CCT CAC CAA CAT TGC TT & GGC CCT GTG ACA TCC TTA GA \\
hs EPOR & TAC AGA GGG TGG AGA TCC & GAT CTT CTG CTT CAG AGC C \\
hs EpoR-s & GGA GCC AGG GCG AAT CAC AGG & GCC TTC AAA CTC GCT CTC TG \\
hs CyclinD1 & AAC TAC CTG GAC CGC TTC CT & CCA CTT GAG CTT GTT CAC CA \\
hs PCNA & GCT GTG TAG TAA AGA TGC CT & TAT GGT AAC AGC TTC CTC CT \\
hs Ki67 & CCA GAG GAA GTA TTC CTA CAG & CCC TCA CTC TCA TTA ATG GA \\
hs GADPH & AGC CCA GAA CAT CAT CCC TG & CCC CAC CTT CTT GAT GTC ATC \\
hs $\beta$-actin & CTG GCA CCC AGC ACA ATG & CCG ATC CAC ACG GAG TAC TTG \\
\hline
\end{tabular}

\section{Results}

Aberrant gene expression of the EPO/EpoR axis during chronic liver damage and $\mathrm{CC}$ development

As indicated in the RT-PCR analyses, the expression of EPO mRNA progressively increased up to $24.7 \pm 9.9$-fold reaching a maximum at week 18 and $16.1 \pm 3.5$ in the isolated CC (extracted tumor tissue) from 18 weeks TAAtreated livers $(* P \leq 0.05)$ (Fig. 1a). Interestingly, already after 4 weeks of treatment, the expression started to increase and became statistically significant at week 8 , therefore indicating an EPO overproduction preceding the appearance of tumor. This early increase was clearly reproduced also at the protein level in the Western blot images (Fig. 1c). In fact, the EPO band $(\sim 34 \mathrm{kDa})$ showed an increase already at 4 weeks after the treatment became progressively stronger after 8 weeks of treatment, and persisted until the cancer nodules appeared. Recombinant rat EPO was used as positive control (Fig. 1c).

The mRNA levels of EpoR showed a similar and parallel up-regulation with a maximum at week 18 $(15.5 \pm 1.1$-fold $)(* P \leq 0.05)$. Furthermore, EpoR mRNA expression analyzed in the excised tumor was $14.6 \pm 2.9$ fold higher than in the normal liver (Fig. 1b). The immunoblot for EpoR ( 56 kDa) showed a clear increase in the signal already after 4 weeks of treatment and remained strongly expressed at all time points analyzed (Fig. 1d).

Identification of EPO-producing cells in rat liver during TAA administration

According to previous studies (Weidemann and Johnson 2009), EPO production in the normal liver might be attributed mainly to the hepatocytes surrounding the central veins (Fig. 2a, b), although recent unpublished data from our group suggest Kupffer cells and HSC as possible contributors to hepatic EPO production. The immunostaining reported here showed a progressive increment in EPO synthesis that already rose up at early stages after TAA treatment (4-8 weeks) (Figs. 2c, d, 3a, b). As the fibrotic process progressed (Fig. 3c, d), the isolated nodules of regenerating hepatocytes between the fibrotic septa revealed an increased positivity that is well illustrated in the APAAP images obtained at weeks 8 (Fig. 3a, b), 12 (Fig. 3c, d) and 16 (Fig. 4a, b). Gradually, EPO-positive bile ducts secondarily appeared, although not all the proliferating bile ducts seemed to participate in EPO production, as clearly shown in the histological analyses of Fig. 3d (short arrows). In fact, the EPO expression in cholangiocytes grew in a time-dependent manner and became particularly elevated in the hyperplastic bile ducts of the cancer tissue, where it was, however, possible to individuate isolated clusters of negative bile ducts (Fig. 4c, d).

Immunolocalization of the EpoR in the rat liver during TAA administration

As presented in Fig. 5, no evident co-localization of EpoR and Hep Par-1 was detectable by immunostaining, indicating a very low expression of the receptor in rat hepatocytes (Fig. 5a, c). In normal liver, rare bile ducts and hepatic vessels showed a weak positivity for EpoR antibody (Figs. 5a, 6a). During chronic injury, increased EpoR protein expression was localized in the sinusoids of the regenerating nodules (Fig. 5b, c), suggesting an important role for tissue vascularization, and in the $\mathrm{CK} 19^{+}$hyperplastic cells of the $\mathrm{CC}$ (Fig. 6b, c). Moreover, merge signals co-localizing with EpoR antibodies have also been identified in ED-2 positive cells, although the sinusoidal location hardly allows discrimination with endothelial cells 


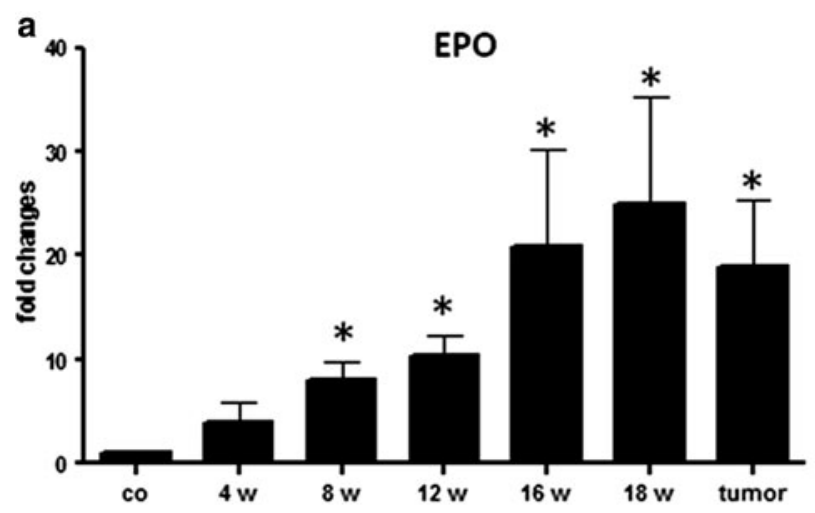

C
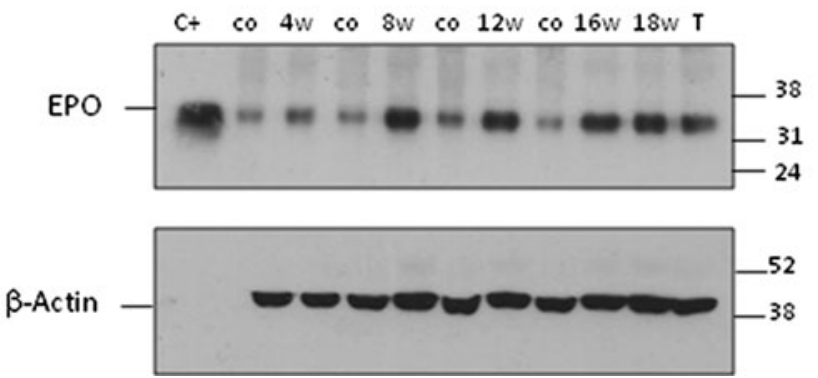

Fig. $1 \mathrm{mRNA}$ and protein expression levels of EPO and EpoR in TAA-treated rats. a Number of EPO RNA transcripts expressed in fold changes relative to Ubiquitin $\mathrm{C}$ gene expression ( $t$ test statistical analysis was performed at each time point vs. control group, $* P<0.05$ and $* * P<0.01, N=4 / 5)$. b Number of EpoR RNA transcripts expressed in fold changes relative to Ubiquitin $\mathrm{C}$ gene

(Fig. 7). No alpha-SMA positive cells were found to be positive for EpoR antibody (Fig. 8).

EPO and EpoR mRNA expression in isolated rat liver cells

To confirm previously described in vivo observations, we analyzed the expression of EPO and EpoR in freshly isolated parenchymal and non-parenchymal rat liver cells. As expected, under normoxic and un-stimulated conditions, the hepatocytes expressed only modest levels of both EPO and EpoR gene expression as absolute value. Although RNA levels were detectable in all studied cell populations, hepatocytes and myofibroblasts showed the highest EPO gene expression levels (Fig. 9a), while EpoR gene expression was predominantly seen in isolated Kupffer cells and endothelial cells (Fig. 9b).

EPO and EpoR mRNA expression in different human cell lines

Considering in advance that CK- $19^{+}$cells were $\mathrm{EpoR}^{+}$by performing immunohistochemistry analysis (Fig. 6), we decided to employ human $\mathrm{CC}$ and $\mathrm{HCC}$ cell lines for our in
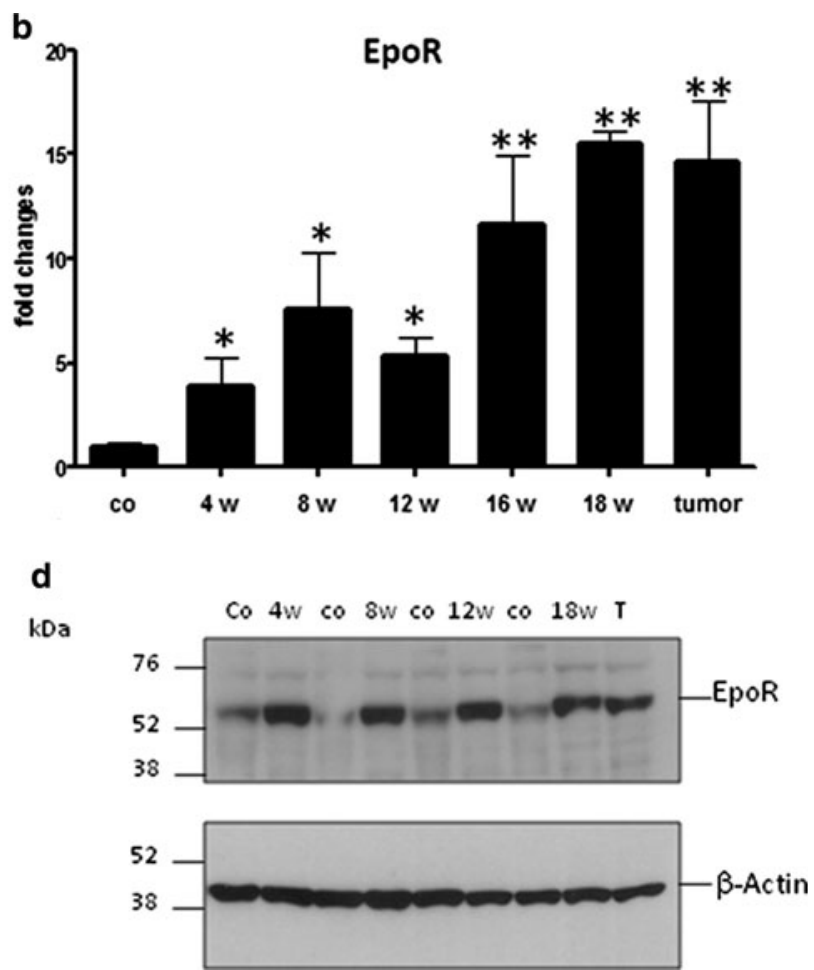

expression ( $t$ test statistical analysis was performed at each time point vs. control group, $* P<0.05$ and $* * P<0.01, N=4 / 5)$. Representative Western blot for EPO (c) and EpoR (d) protein levels in total liver and excised tumors protein extracts. $C o$ indicates respective rat control liver for every time point analyzed. Recombinant rat EPO was used as positive control $(\mathrm{C}+)$

vitro studies. The number of EPO gene transcripts in hepatoma and specifically in the human CC cell line Mz-Cha-2 increased significantly compared to normal hepatocytes (Fig. 9c). Whereas other CC cell lines presented expression levels similar to primary hepatocytes, quantification by PCR revealed a particularly high expression in Mz-Cha-2, although the HCC cell line HepG2 showed the highest number of transcripts in un-stimulated conditions (Fig. 9c).

Analysis of the EpoR gene was conducted for the two transcripts that code for different peptide isoforms of the receptor, the full-length (EpoR) and the soluble form (EpoR-s) derived from alternative splicing (Arcasoy et al. 2003). The identification of the two clones enabled a selective PCR analysis in human cell lines. Interestingly, EpoR gene expression was plainly detectable in these cell lines, whereas EpoR-s expression was barely detectable (Fig. 9d).

Changes of EpoR gene expression after SCF treatment in combination with EPO in different human CC cell lines

We investigated also the effects of SCF (c-kit ligand), a growth factor that we described in the same experimental 

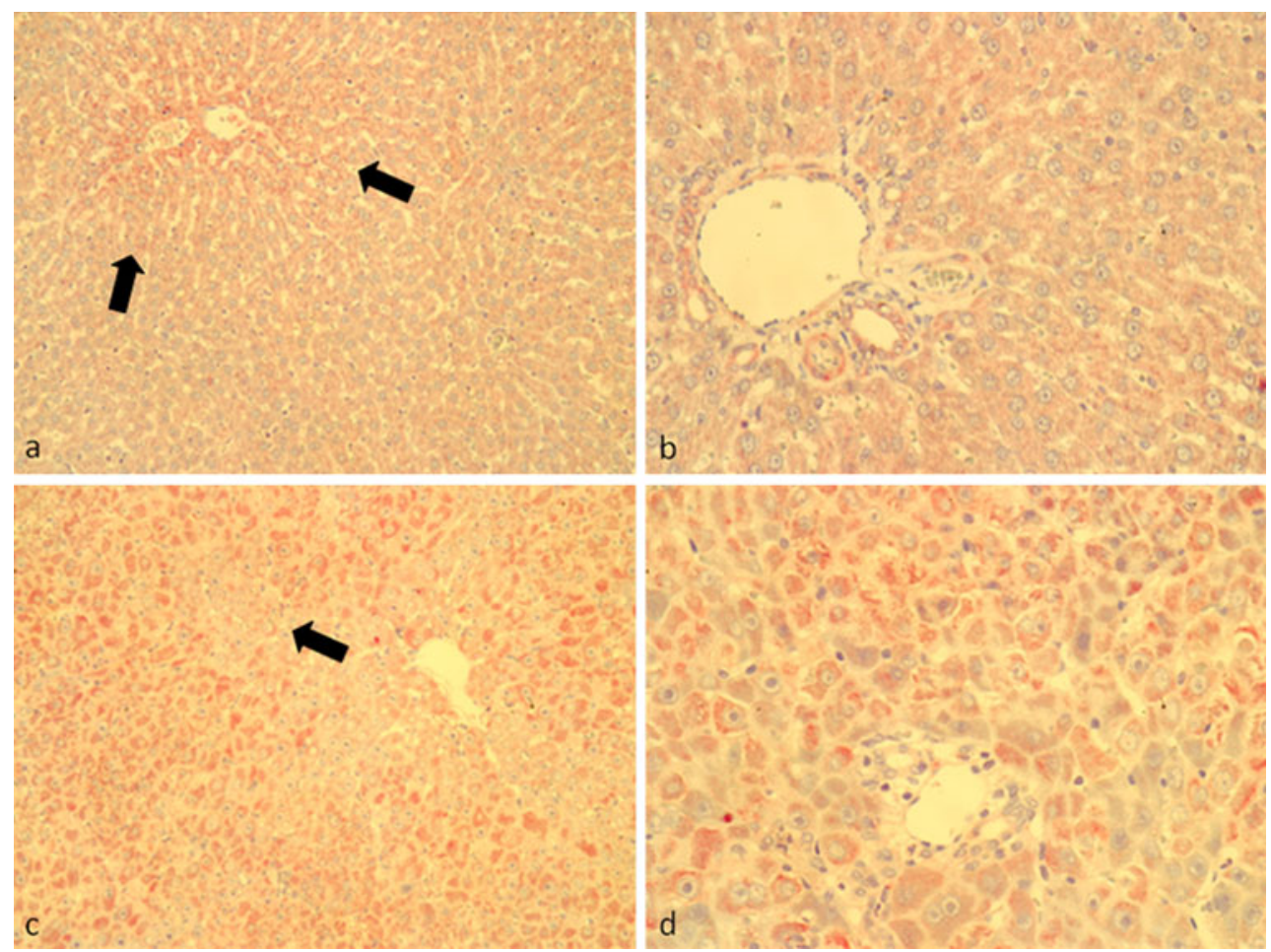

Fig. 2 Immunohistochemical detection of EPO with alkaline phosphatase anti-alkaline phosphatase (APAAP)/Fast Red method in rat liver sections. a Perivenular $(\times 100)$ and $\mathbf{b}$ periportal $(\times 200)$ spaces in normal control livers. EPO was moderately expressed in hepatocytes

surrounding perivenular spaces (large arrows). c Perivenular and d periportal spaces in 4 weeks TAA-treated rats $(\times 100$ and $\times 200$, respectively)

model (Mansuroglu et al. 2009) and that was previously identified in the same cell lines (Kamenz et al. 2006). We analyzed the human CC cell line Mz-Cha-2 and found no significant changes of EpoR or EpoR-s gene expression after stimulation with the growth factors EPO and SCF, alone or in combination (Fig. 10a). We performed the same experiments in the other CC cell lines, TFK-1 and EGI-1 (Fig. 10a). While in this last cell population (c-kit negative cells, Shi et al. 2010) we were unable to detect significant changes for the same genes following growth factor stimulation (data not shown) in spite of an evident presence of EpoR protein (Fig. 10b), surprisingly in TFK-1 we observed a decrease in EPO production in parallel with a decrease in CyclinD1 and PCNA expression after treatment with a combination of SCF and EPO (data not shown), in contrast to a significant increase of EpoR-s transcripts (Fig. 10a). Beyond increasing the level of complexity, this result suggests a diverse responsiveness of $\mathrm{CC}$ cells based on the presence of different growth factors in the extracellular milieu.

To investigate the presence of different EpoR isoforms, i.e., a soluble- (EpoR-s), truncated (EpoR-t) and a fulllength (EpoR-f) isoform (here indicated as EpoR), we performed a Western blot analysis using an EpoR-specific antibody (3D10 clone) recognizing the extracellular

domain of the receptor (Supplementary Fig. 1). EpoR protein levels were detectable only for EpoR as shown in Fig. 10b $(\sim 56 \mathrm{kDa})$. In every cell population, we could not detect EpoR-s $(\sim 28 \mathrm{kDa})$ or EpoR-t $(\sim 35 \mathrm{kDa})$ isoforms (Fig. 10b).

SCF treatment in combination with EPO induced significant changes in EPO gene expression and of cell cycle genes on human Mz-Cha-2 cell line

The functional activity of the EPO/EpoR axis was verified in Mz-Cha-2 cell line which was shown to express the highest EPO levels under normoxic condition. Firstly, a dose-dependent assay of the effect on cell cycle gene expression was performed with different concentration of EPO at $0.1,1$ and $10 \mathrm{U} / \mathrm{ml}$ and evaluated $24 \mathrm{~h}$ after the treatment. The results indicated a dose-dependent response of Ki67 and PCNA genes (Fig. 11a). Over a period of 48 h, EPO at a concentration of $10 \mathrm{U} / \mathrm{ml}$ enhanced PCNA gene expression in Mz-Cha-2 compared to untreated controls (Fig. 11b).

We also investigated the effects of SCF in the same cell line. Interestingly, although the stimulation with SCF alone did not show any significant increase in CyclinD1 and PCNA gene expression, challenging Mz-Cha-2 cells with a 

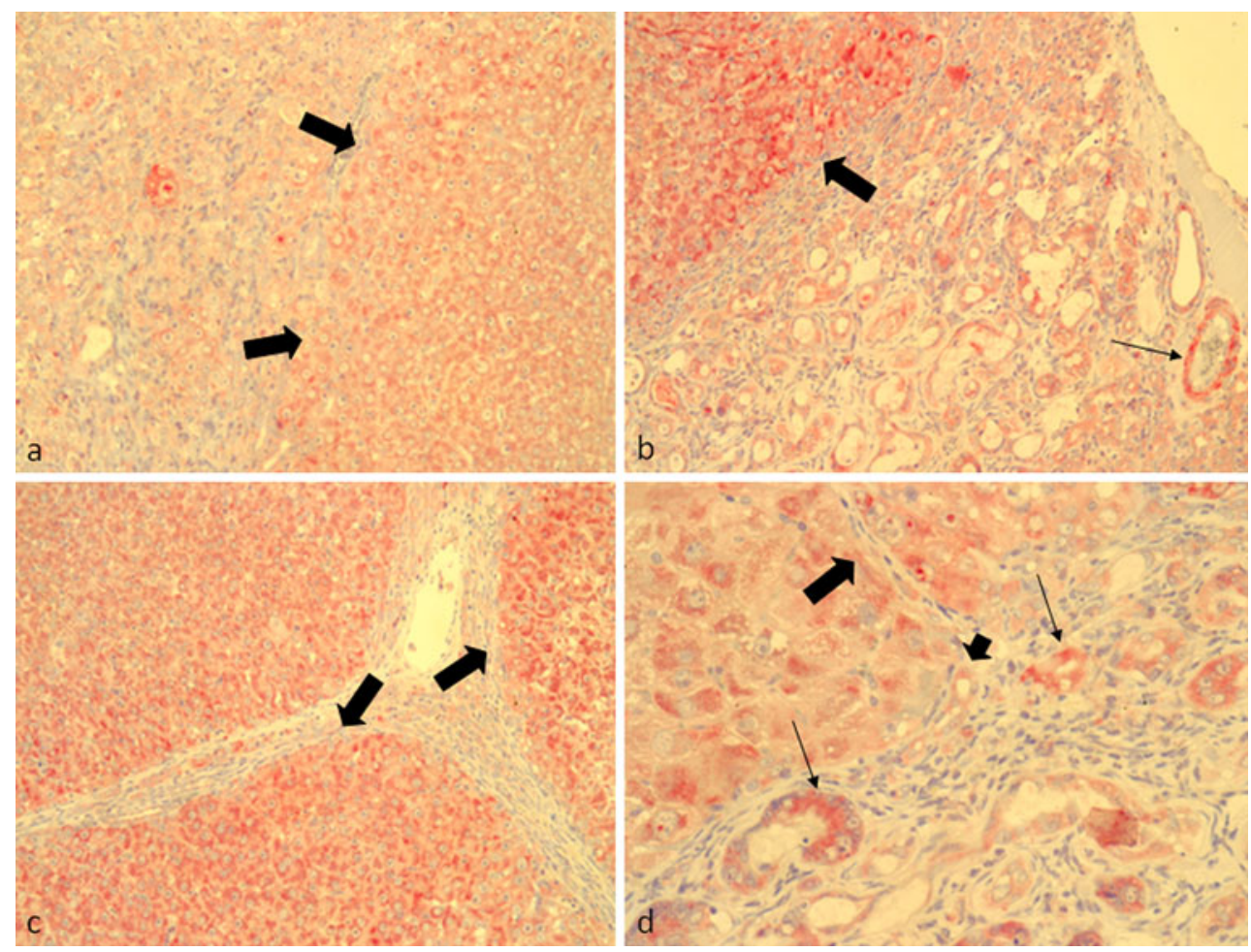

Fig. 3 Immunohistochemical detection of EPO with alkaline phosphatase anti-alkaline phosphatase (APAAP)/Fast Red method in rat liver sections. a, b Internodular $(\times 100$ and $\times 200)$ spaces of 8 weeks TAA-treated rats and $\mathbf{c}, \mathbf{d}$ of 12 weeks TAA-treated rats. At this time

combination of EPO and SCF resulted in a significant increase in EPO gene expression (more than $100 \%$ increase) and in a significant $70 \%$ augmentation of CyclinD1 and $50 \%$ of PCNA (Fig. 11c).

\section{Discussion}

The existence of the EPO/EpoR signaling pathway has been recently observed in a wide range of tumors and cancer cell line (Sinclair et al. 2007), but its role and true function in the context of cancer biology are still a matter of controversy and currently under investigation. Although classical investigation of partial hepatectomy indicated an important synthesis of the hormone accompanying liver regeneration and restoration of the liver mass (Bockhorn et al. 2008) and recent studies revealed that an increased EPO gene expression was associated with promotion of synaptic plasticity in an experimental model of nervous system injury (Mengozzi et al. 2012), the importance of this hormone in this particular context is still underestimated.

Overproduction of EPO has been described in several tumor conditions among others in the liver, where it has been associated mainly with its angiogenic properties

point, EPO positivity is mainly localized in the regenerating nodules inter-septa (large arrows) and in isolated hyperplastic bile ducts (thin arrows). The presence of EPO-negative bile ducts is indicated by short arrow

(Ribatti et al. 2007). However, the presence of the EpoR on tumor cell lines has led to disparate interpretations. In fact, whereas many studies have reported an increase in EPO levels in terms of protein expression, the lack of specificity of commercially available antibodies has limited the understanding of a potential functional role of this pathway under these pathological conditions (Fandrey 2008). The hepatic reactivation of EPO production has been shown to occur in several clinical and experimental pathological conditions, such as acute phase response and acute liver injury and repair (Ramadori et al. 2010a), but the mechanisms and the physiological consequences of this switch remain unclear.

In the present work, we investigated the expression of the hormone and its receptor in an experimental model of chronic liver injury that leads to the development of intrahepatic CC. In detail, the chronic administration of TAA in drinking water has been shown to induce hepatic injury with periportal fibrosis that evolves to cirrhosis and endstage neoplastic transformation of the hyper-proliferative bile ducts within the stromal tissue of the portal spaces (Mansuroglu et al. 2009).

We analyzed EPO production by evaluating gene expression and confirming it by protein detection. Its synthesis and production increased progressively up to 

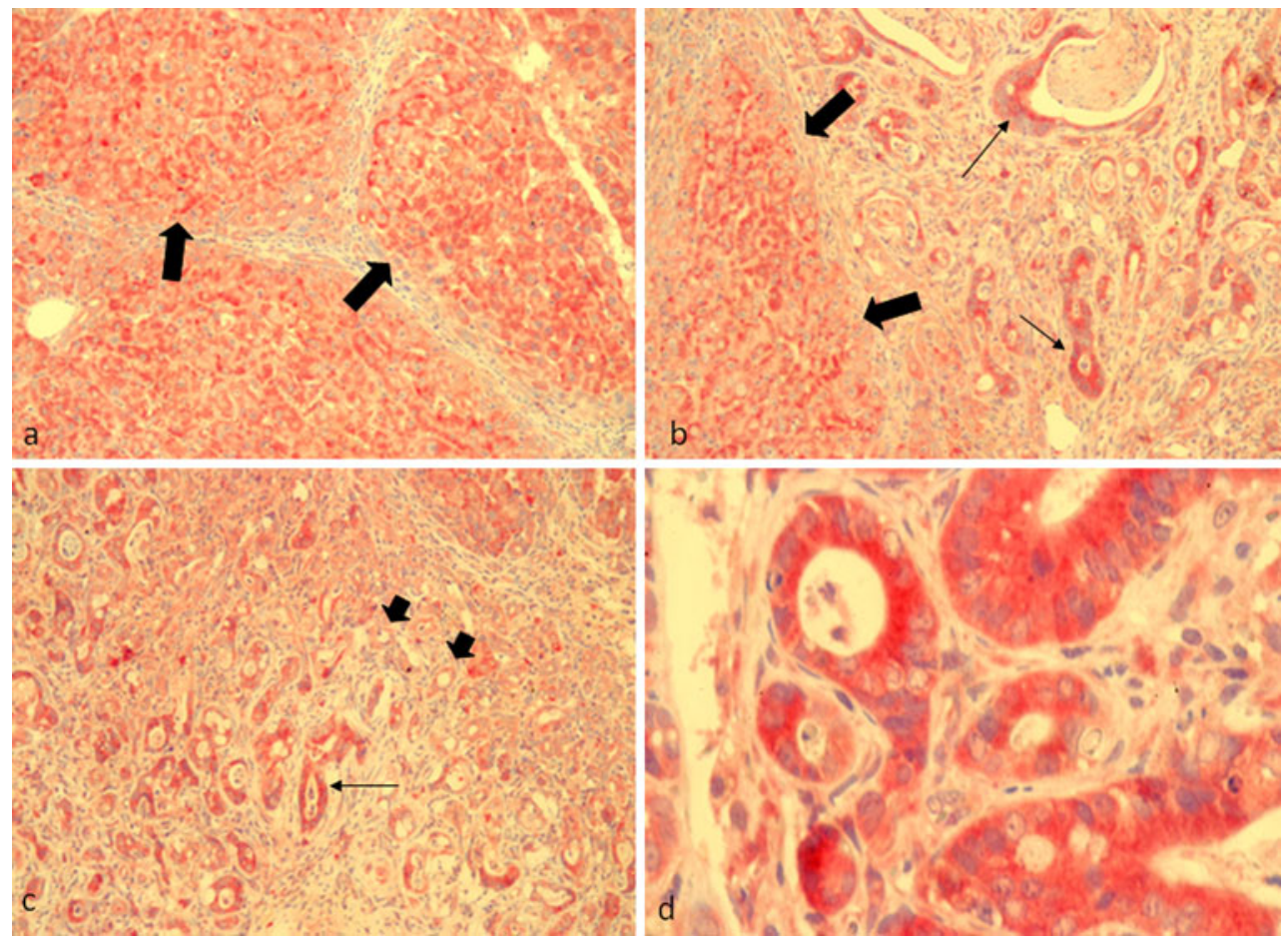

Fig. 4 Immunohistochemical detection of EPO with alkaline phosphatase anti-alkaline phosphatase (APAAP)/Fast Red method in rat liver sections. a, b Three regenerative nodules $(\times 100$ and $\times 200)$ separated by (negative) fibrotic septa of 16 weeks TAA-treated rats and $\mathbf{c}, \mathbf{d}$ a particular part of the tumor area of 16 weeks TAA-treated rats. EPO positivity is mainly localized in the regenerating nodules intersepta (large arrows) and hyperplastic bile ducts (thin arrows). Not all proliferating bile ducts seem to participate in EPO production (c short arrows). d Details of a CC area at higher magnification $(\times 400)$
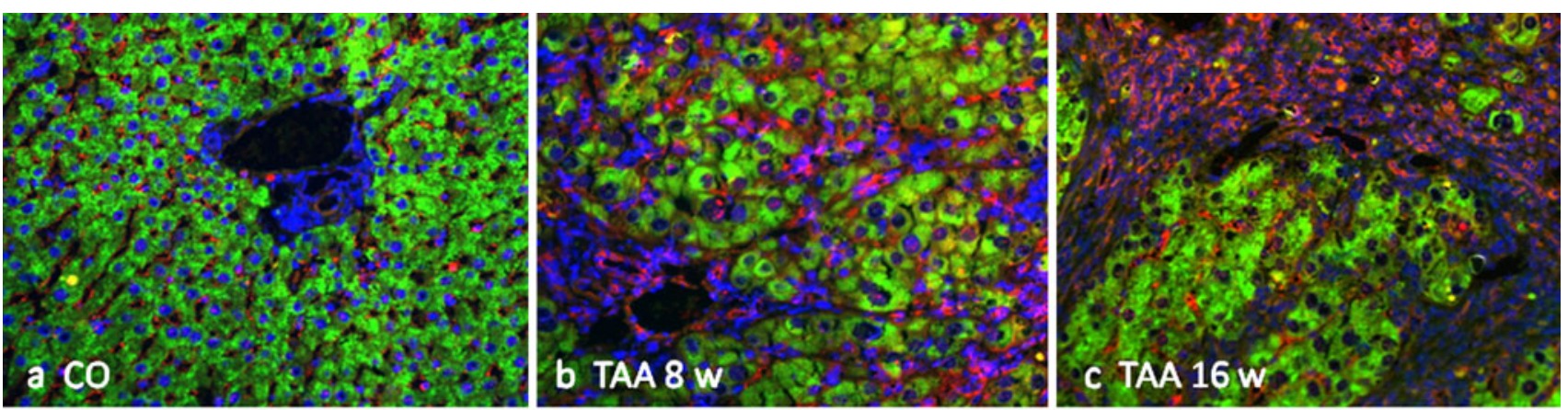

Fig. 5 Co-localization image of a double immunofluorescence stain for EpoR (red channel) and the hepatocyte-specific marker Hep Par-1 (green channel). Representative images of periportal spaces of a normal control, b 8-week-treated and c 16-week-treated TAA rat

18 weeks as illustrated by mRNA expression and Western blot analysis. Immunohistochemistry indicated a localization of the hormone that was particularly abundant in hepatocytes of the regenerating cirrhotic nodules and in the dysplastic proliferating bile ducts that were progressively transforming. The metabolic increase required for proliferation and possibly the altered oxygen tension might livers at $\times 200$. Sections were analyzed with an epifluorescence microscope and the images were obtained with AxioVision system software

reasonably explain the high expression levels of EPO seen already at 4 weeks after treatment. In line with these observations, it is also interesting to mention a recent study on EPO expression during tumor development in which tumor-derived PDGF-BB was shown to induce a dramatic increase of circulating EPO responsible for tumor growth promotion, angiogenesis and hematopoiesis. Importantly, 

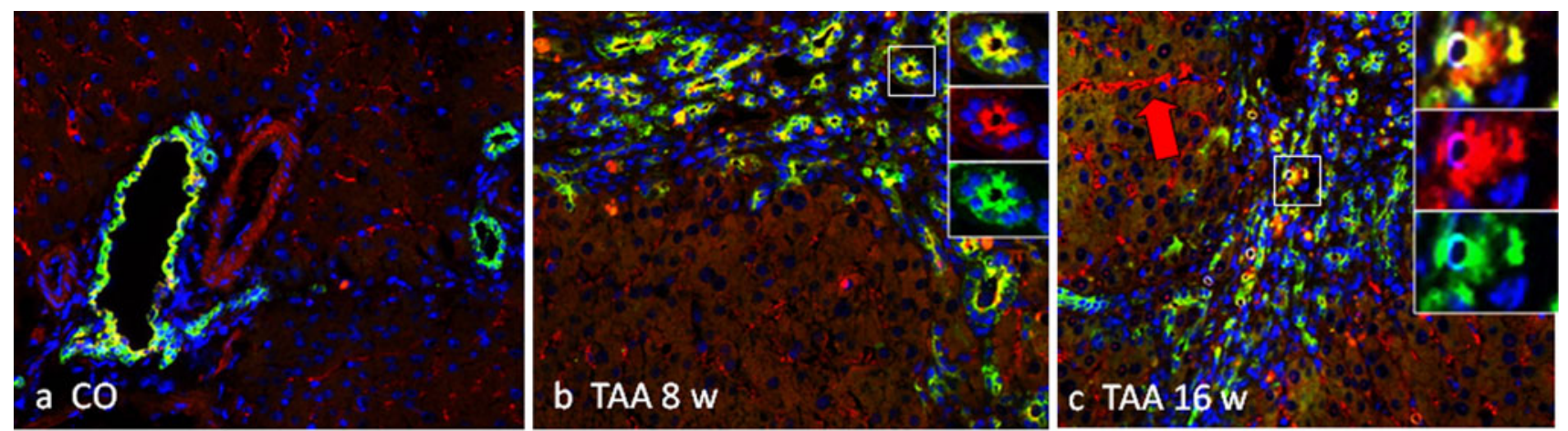

$$
\text { EpoR (red) + CK19 (green) }
$$

Fig. 6 Co-localization image of a double immunofluorescence stain for EpoR (red channel) and the cholangiocyte-specific marker CK19 (green channel). Representative images of periportal spaces of a normal control, b 8-week-treated and c 16-week-treated TAA rat livers at $\times 200$. In $\mathbf{b}$ and $\mathbf{c}$ it is possible to appreciate the detailed merge images of double positive (CK19/EpoR) bile ducts and a clear intra-nodular sinusoidal positivity (c red arrow). Sections were analyzed with an epifluorescence microscope and images were obtained with AxioVision system software
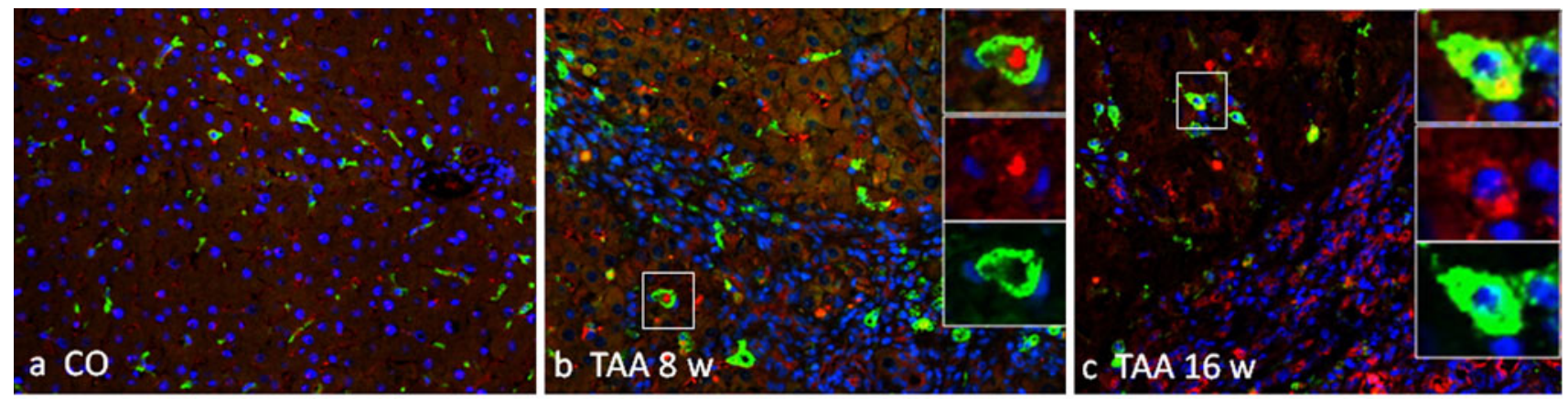

$$
\operatorname{EpoR}(\text { red) }+E D-2 \text { (green) }
$$

Fig. 7 Co-localization image of a double immunofluorescence stain for EpoR (red channel) and the macrophage-specific marker ED-2 (green channel). Representative images of periportal spaces of a normal control, b 8-week-treated and c 16-week-treated TAA rat

livers at $\times 200$. At higher magnification, merged images indicate a possible co-localization of EpoR with ED-2. Sections were analyzed with an epifluorescence microscope and images were obtained with AxioVision system software
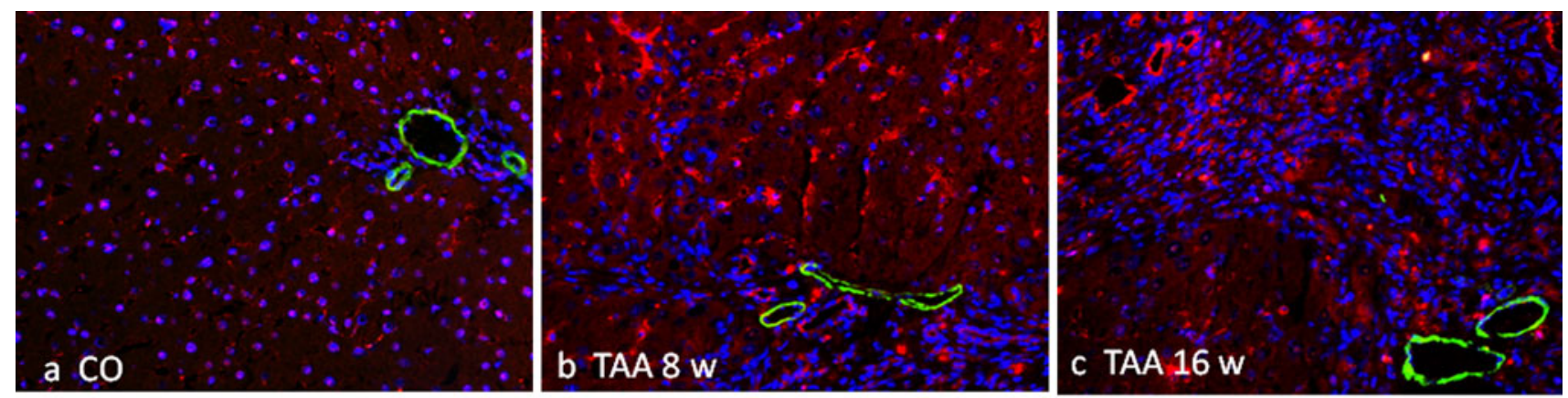

$$
\operatorname{EpoR}(\text { red) }+\alpha-S M A(\text { green) }
$$

Fig. 8 Co-localization image of a double immunofluorescence stain for EpoR (red channel) and alpha smooth muscle actin (green channel). Representative images of periportal spaces of a normal control, b 8-week-treated and c 16-week-treated TAA rat livers at $\times 200$. No evident co-localization signals were detected. Sections were analyzed with an epifluorescence microscope and images were obtained with AxioVision system software 

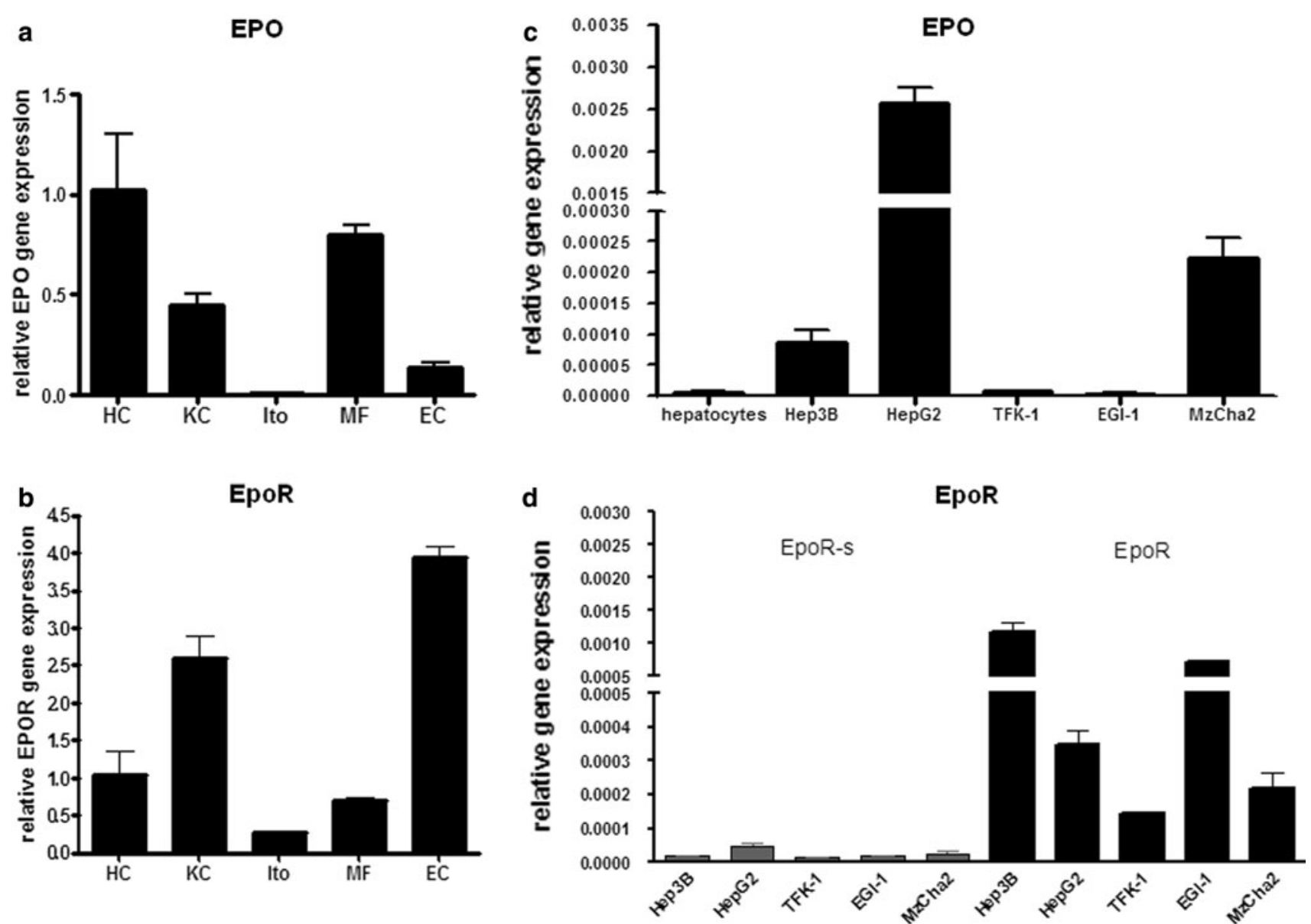

Fig. 9 EPO (a) and EpoR (b) gene expression in liver parenchymal and non-parenchymal cells isolated from normal rat livers compared to rat primary hepatocytes. Relative levels of EPO (c) and EpoR (d) gene expression in different human hepatoma and CC cell lines

the major sources of EPO in these specific conditions were identified in liver and spleen, but not in the kidneys (Xue et al. 2012).

EPO gene expression during hypoxia and the high expression levels observed in hepatoma cell lines have been classically associated with the activation of the transcription factor family HIFs, hypoxia-inducible factor. In this context, evidences concerning the direct transcriptional regulator of the EPO gene in the liver (HIF-1 or HIF-2) are still the subject of intense debate. However and interestingly, a recent genomic report by Steinmann et al. (2011) conducted on several cancer cell lines identified the hepatoma cell line Hep3B as the tumor cell population with the highest EPO expression in a wide range of cells, higher even than renal cancer cells. Of note, Steinmann et al. were able to demonstrate that this peculiarity of gene expression might be due to the lack of methylation of the EPO promoter in this cell population, indicating a further mechanism of transcriptional control. In fact, our analyses revealed a higher expression of EPO transcripts in normal HepG2 cells compared to Hep3B, and we were able to collocate the $\mathrm{CC}$ cell line $\mathrm{Mz}-\mathrm{Cha}-2$ among the different examined $\mathrm{CC}$ cell lines expressing the highest levels of EPO in absolute value.

We used the polyclonal antibody (M-20) previously shown to have a reliable specificity (Lopez et al. 2011) to identify the EpoR by Western blot and immunohistochemistry, since the anti-EpoR antibody (C-20 Santa Cruz Biotech) has been reported to cross-react with HSP70, which is also highly expressed in tumor tissue (Brown et al. 2007). Interestingly, the detection of an approximately $59 \mathrm{kDa}$ band by Western blot using the polyclonal M-20 antibody suggested the significantly overexpressed presence of the EpoR in liver tissue during CC development, as also confirmed by RT-PCR analysis.

A recent study by Khankin et al. (2010) reported the presence of a soluble form of EpoR (EpoR-s) in the serum of dialysis patients detectable as a $28 \mathrm{kDa}$ protein resulting from an alternative mRNA splicing. Interestingly, the expression of EpoR-s was shown to be induced by proinflammatory cytokines and its circulating levels were correlated with increased peripheral EPO resistance. In contrast, although we could detect a very low number of EpoR-s transcripts in the CC cells analyzed in our study, 


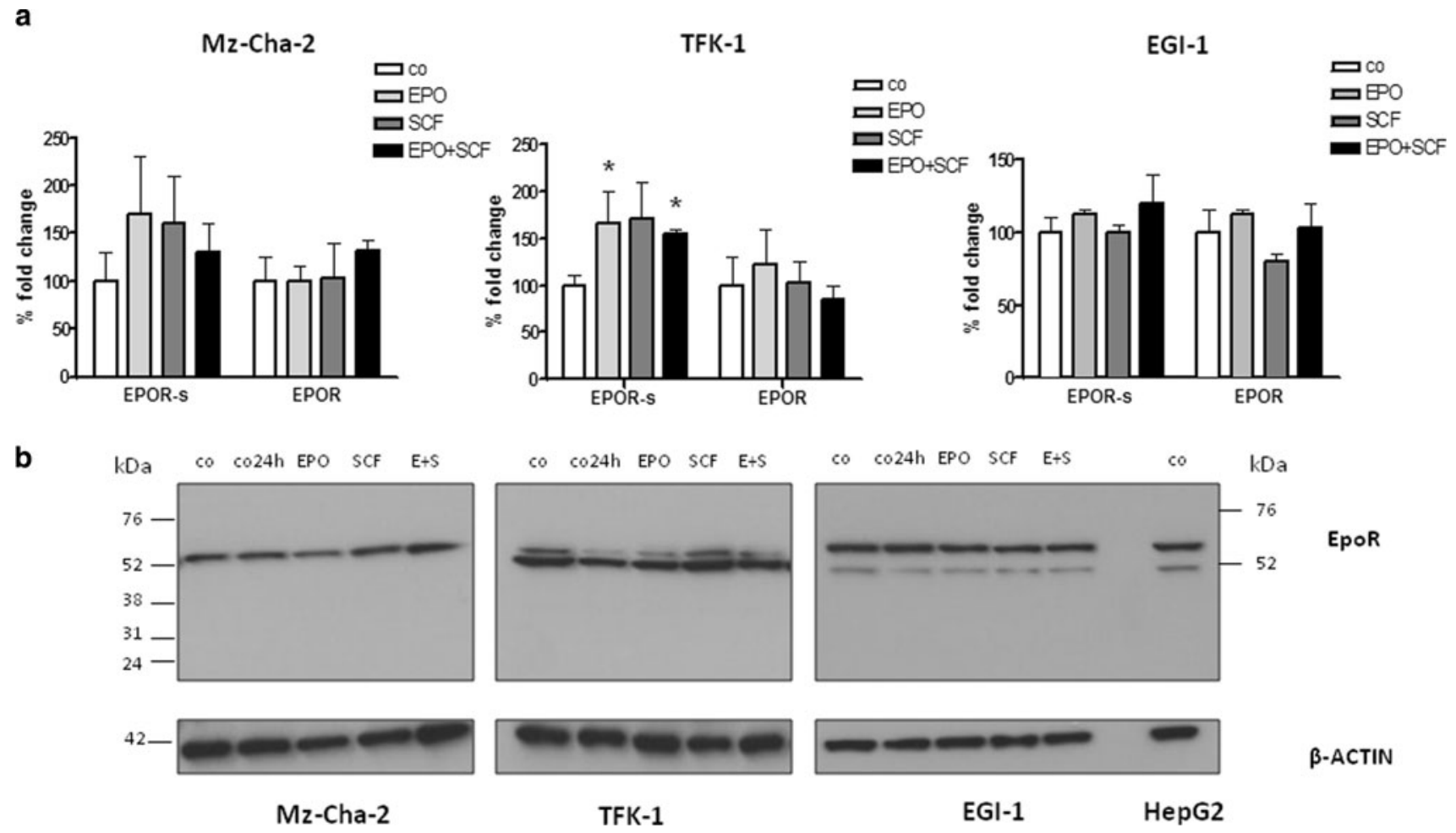

Fig. 10 EpoR gene expression in three $\mathrm{CC}$ cell lines challenged with EPO $(10 \mathrm{U} / \mathrm{ml})$, SCF $(10 \mathrm{ng} / \mathrm{ml})$ or a combination of both growth factors for $24 \mathrm{~h}$ under serum-free conditions. a Gene expression of different EpoR isoforms [full length (EpoR) and soluble (EpoRs)] was analyzed in all three indicated CC cell populations following growth factor challenge (Mz-Cha-2, TFK-1, and EGI-1). b Western blot analysis performed after cell stimulation indicates the presence of EpoR protein in all cell lines using an EpoR antibody for the extracellular domain. Co indicates control cells in un-stimulated conditions and not starved, whereas Co $24 \mathrm{~h}$ refers to untreated starved control cells. HepG2 protein extract was used as a positive control
Fig. 11 Cell proliferation gene expression in Mz-Cha-2 cells challenged for $24 \mathrm{~h}$ with EPO $(10 \mathrm{U} / \mathrm{ml}), \mathrm{SCF}(10 \mathrm{ng} / \mathrm{ml})$ or a combination of both. a Ki67 and PCNA gene expression was evaluated after a dosedependent challenge with recombinant human EPO. b PCNA expression was analyzed in a range of $48 \mathrm{~h}$ using two different EPO concentrations ( 1 and $10 \mathrm{U} / \mathrm{ml}$ ). c EPO responsiveness of Mz-Cha-2 was investigated by analyzing EPO, CyclinD1 and PCNA gene expression after $24 \mathrm{~h}$ of incubation with the growth factors as indicated above
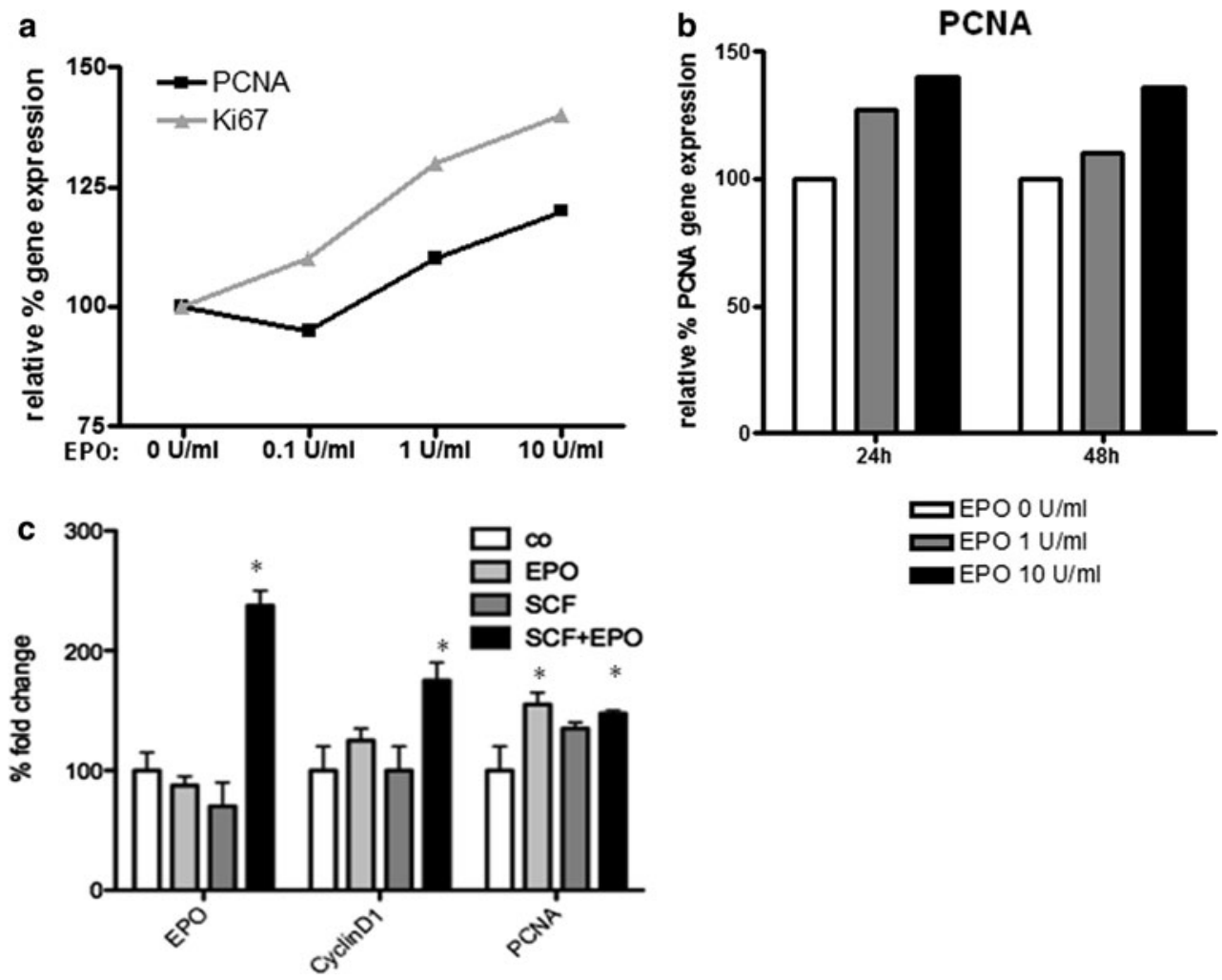
we could not identify any bands other than a $56 \mathrm{kDa}$ by Western blot using a reliable monoclonal EpoR antibody (clone 3D10).

The localization of EpoR by immunohistochemistry confirmed previous studies on chemically induced hepatocellular carcinoma in mice (Nakamatsu et al. 2004), indicating the presence of the receptor in the sinusoids within the regenerative nodules and supporting an important role of EPO in the vasculogenesis and angiogenesis related to disturbances of the circulatory tree in the cirrhotic liver that are crucial for the expansion and proliferation of the tumor. On the other hand, CC cells localized in the hyperplastic biliary ducts also showed detectable amounts of EpoR as demonstrated in the co-localization staining with CK19. Furthermore, we found high levels of EpoR transcripts in isolated Kupffer cells, and isolated clusters of ED-2 positive cells in TAA-treated livers showed signals of positivity for the EpoR antibody. Although it seems immature to draw conclusions in this direction, a recent observation by Broxmeyer (2011) might suggest a possible role for EPO in the re-organization of the tumor-associated immune response (Broxmeyer 2011).

To elucidate the functional role of EPO/EpoR signaling in cell proliferation and/or cell survival, we analyzed the effects of EPO stimulation on genes involved in the cell cycle, such as PCNA and CyclinD1, as previously observed in other cancer cell lines (Feldman et al. 2006). Upon binding to its receptor, EPO leads to a dimerization and transphosphorylation which triggers proliferating and anti-apoptotic pathways. This in turn initiates additional specific signal transduction pathways, including the phosphatidylinositol 3-kinase (PI-3K)/AKT pathway, MAPKs family member cascade and the JAK/STAT pathway, which are fundamental not only for hepato-protective signaling, but also in liver regeneration and repair (Gao 2005) Indeed, in Mz-Cha-2, the cell line with the highest EPO gene expression, a modest but dose-dependent increase of the two downstream genes was observed under normoxic conditions.

Finally, referring to previous reports from our group (Mansuroglu et al. 2009) and others (Kamenz et al. 2006) showing an aberrant expression of the SCF/-c-kit pathway in the same experimental model, a synergistic effect of SCF and EPO on cell functions was hypothesized. In particular, the cell populations that express the highest levels of c-kit receptor, hepatocytes of the cirrhotic nodules and hyper-proliferative CK19-positive cells, were found to be the same cell types that contribute to the greatest extent to EPO production. Moreover, during erythropoiesis and in the fetal liver, the crosstalk between these growth factors has been shown to induce proliferation and differentiation of erythroid progenitor cells through signals commonly triggering JAK2/STAT5 phosphorylation and activation (Wu et al. 1997; Arcasoy and Jiang 2005). The synergistic effect of EPO and SCF on EPO production observed under normoxic condition in Mz-Cha-2 cells, with a concomitant increase of EPO gene expression, PCNA and CyclinD1, indicates a sensitization to EPO responsiveness as already observed in another cancer cell line (Sato et al. 1998). This result might offer new evidence for a possible, hypothesized hematopoietic origin of CC cancer cells (Cardinale et al. 2012).

In conclusion, evidence of an efficacious proliferative challenge for tumor cells remains elusive and requires further in vitro and in vivo investigations (Aapro et al. 2012). We described new tumor cell populations that are able to synthesize EPO in vivo and in vitro, but respond differently to stimulation. This study reaffirmed the importance of EPO as a molecular mediator produced by the liver during the process of chronic hepatic injury and regeneration in its progression to cancer.

Acknowledgments The authors are thankful to Mrs Sonja Heyroth, Mrs Anke Herbst and Mrs Elke Neumann for their skillful assistance.

Open Access This article is distributed under the terms of the Creative Commons Attribution License which permits any use, distribution, and reproduction in any medium, provided the original author(s) and the source are credited.

\section{References}

Aapro M, Jelkmann W, Costantinescu SN, Leyland-Jones B (2012) Effects of erythropoietin receptors and erythropoiesis-stimulating agents on disease progression in cancer. $\mathrm{Br} \mathrm{J}$ Cancer 106(7):1249-1258

Arcasoy M, Jiang X (2005) Co-operative signaling mechanism required for erythroid precursor expansion in response to erythropoietin and stem cell factor. Br J Haematol 130:121-129

Arcasoy MO, Jiang X, Haroon ZA (2003) Expression of erythropoietin receptor splice variants in human cancer. Biochem Biophys Res Commun 307:999-1007

Armbrust T, Kreissig M, Tron K, Ramadori G (2004) Modulation of fibronectin gene expression in inflammatory mononuclear phagocytes of rat liver after acute liver injury. J Hepatol 40(4):638-645

Bockhorn M, Fingas CD, Rauen U, Canbay A, Sotiropoulos GC, Frey U, Sheu SY, Wohlschläger J, Broelsch CE, Schlaak JF (2008) Erythropoietin treatment improves liver regeneration and survival in rat models of extended liver resection and living donor liver transplantation. Transplantation 86:1578-1585

Brines M, Cerami A (2012) The receptor that tames the innate immune response. Mol Med 18:486-496

Brown WM, Maxwell P, Graham AN, Yakkundi A, Dunlop EA, Shi Z, Johnston PG, Lappin TR (2007) Erythropoietin receptor expression in non-small cell lung carcinoma: a question of antibody specificity. Stem Cells 25:718-722

Broxmeyer HE (2011) Erythropoietin surprises: an immune saga. Immunity $34: 6-7$

Cardinale V, Wang Y, Carpino G, Reid L, Gaudio E, Alvaro D (2012) Mucin-producing cholangiocarcinoma might derive from biliary 
tree stem/progenitor cells located in peri biliary glands. Hepatology 55:2041-2042

Cheng TI, Tsou MH, Yang PS, Sung SM, Chuang VP, Sung JL (2002) Dermatomyositis and erythrocytosis associated with hepatocellular carcinoma. J Gastroenterol Hepatol 17(11):1239-1240

Fandrey J (2008) Erythropoietin receptors on tumor cells: what do they mean? Oncologist 13(Suppl):316-320

Farrell F, Lee A (2004) The erythropoietin receptor and its expression in tumor cells and other tissues. Oncologist 9(Suppl 5):18-30

Feldman L, Wang JS, Rhim N, Bhattacharya N, Loda M, Sytkowski AJ (2006) Erythropoietin stimulates growth and STAT5 phosphorylation in human prostate epithelial and prostate cancer cells. Prostate 66:135-145

Gao B (2005) Cytokines, STATs and liver disease. Cell Mol Immunol 2(2):92-100

Hadland BK, Longmore GD (2009) Erythroid-stimulating agents in cancer therapy: potential dangers and biological mechanisms. J Clin Oncol 27(25):4217-4226

Hedley BD, Allan LA, Xenocostas A (2011) The role of erythropoietin and erythropoiesis-stimulating agents in tumor progression. Clin Cancer Res 17:6373-6380

Kamenz T, Caca K, Blüthner T, Tannapfel A, Mössner J, Wiedmann M (2006) Expression of c-kit receptor in human cholangiocarcinoma and in vivo treatment with imatinib mesilate in chimeric mice. World J Gastroenterol 12(10):1583-1590

Khankin E, Mutter WP, Tamez H, Yuan HT, Karumanchi SA, Thadhani R (2010) Soluble erythropoietin receptor contributes to erythropoietin resistance in end-stage renal disease. PLoS One 5(2):9246-9256

Kumar SM, Zhang G, Bastian BC, Arcasoy MO, Karande P, Pushparajan A, Acs G, Xu X (2011) Erythropoietin receptor contributes to melanoma cell survival in vivo. Oncogene $31: 1649-1660$

Lombardero M, Kovacs K, Scheithauer BW (2011) Erythropoietin: a hormone with multiple functions. Pathobiology 78(1):41-53

Lopez TV, Lappin TR, Maxwell P, Shi Z, Lopez-Marure R, Aquilar C, Rocha-Zavaleta L (2011) Autocrine/paracrine erythropoietin signaling promotes JAK/STAT-dependent proliferation of human cervical cancer cells. Int J Cancer 129(11):2566-2576

Mansuroglu T, Ramadori P, Dudas J, Malik I, Hammerich K, Füzesi L, Ramadori G (2009) Expression of stem cell factor and its receptor c-Kit during the development of intrahepatic cholangiocarcinoma. Lab Invest 89(5):562-574

McKinney M, Arcasoy MO (2011) Erythropoietin for oncology supportive care. Exp Cell Res 317(9):1246-1254

Mengozzi M, Cervellini I, Villa P, Erbayraktar Z, Gökmen N, Yilmaz O, Erbayraktar S, Manohasandra M, Van Hummelen $P$, Vandenabeele P, Chernajovsky Y, Annenkov A, Ghezzi P (2012) Erythropoietin-induced changes in brain gene expression reveal induction of synaptic plasticity genes in experimental stroke. PNAS 109:9617-9622

Nakamatsu K, Nishimura Y, Suzuki M, Kanamori S, Maenishi O, Yasuda Y (2004) Erythropoietin/erythropoietin receptor system as an angiogenic factor in chemically induced murine hepatic tumors. Int J Clin Oncol 9(3):184-188

Neubauer K, Lindhorst A, Tron K, Ramadori G, Saile B (2008) Decrease of PECAM-1-gene-expression induced by proinflammatory cytokines IFN-gamma and TNF-alpha is reversed by TGF-beta in sinusoidal endothelial cells and hepatic mononuclear phagocytes. BMC Physiol 8:9-15

Patel T (2011) Cholangiocarcinoma-controversies and challenges. Nat Rev 8:189-200

Piscaglia F, Dudas J, Knittel T, Di Rocco P, Kobold D, Saile B, Zocco MA, Timpl R, Ramadori G (2009) Expression of ECM proteins fibulin-1 and-2 in acute and chronic liver disease and in cultured rat liver cells. Cell Tissue Res 337(3):449-462

Ramadori P, Ahmad G, Ramadori G (2010a) Cellular and molecular mechanisms regulating the hepatic erythropoietin expression during acute-phase response: a role for IL-6. Lab Invest 90(9): 1306-1324

Ramadori P, Sheikh N, Ahmad G, Dudas J, Ramadori G (2010b) Hepatic changes of erythropoietin gene expression in a rat model of acute phase response. Liver Int 30(1):55-64

Ribatti D, Vacca A, Roccaro AM, Crivellato E, Presta M (2003) Erythropoietin as an angiogenic factor. Eur $\mathrm{J}$ Clin Invest 33(10):891-896

Ribatti D, Marzullo A, Gentile A, Longo V, Nico B, Vacca A, Dammacco F (2007) Erythropoietin/erythropoietin receptor system is involved in angiogenesis in human hepatocellular carcinoma. Histopathology 50(5):591-596

Sato T, Watanabe S, Ishii E, Tsuji K, Nakahata T (1998) Induction of the erythropoietin receptor gene and acquisition of responsiveness to erythropoietin by stem cell factor in HML/SE, a human leukemic cell line. J Biol Chem 273(27):16921-16926

Shi Z, Hodges VM, Dunlop EA, Percy MJ, Maxwell AP, El-Tanani M, Lappin TR (2010) Erythropoietin-induced activation of the JAK2/STAT5, PI3K/Akt, and Ras/ERK pathways promotes malignant cell behaviour in a modified breast cancer cell line. Mol Cancer Res 8(4):615-626

Sinclair AM, Todd M, Forsythe K, Knox SJ, Elliott S, Begley CG (2007) Expression and function of erythropoietin receptors in tumors. Cancer 110:477-488

Steinmann K, Richter AM, Dammann RH (2011) Epigenetic silencing of erythropoietin in human cancers. Genes Cancer 2(1):65-73

Szenajch J, Wcislo G, Jeong JY, Szczylik C, Feldman L (2010) The role of erythropoietin and its receptor in growth, survival and therapeutic response of human tumor cells-from clinic to bench - a critical review. Biochim Biophys Acta 1806(1):82-95

Weidemann A, Johnson RS (2009) Non-renal regulation of EPO synthesis. Kidney Int 75(7):682-688

Wu H, Klingmueller U, Acurio A, Hsiao JG, Lodish HF (1997) Functional interaction of erythropoietin and stem cell factor receptors is essential for erythroid colony formation. PNAS 94(5):1806-1810

Xue Y, Lim S, Yang Y, Wang Z, Jansen LD, Hedlund EM, Andersson P, Sasahara M, Larsson O, Galter D, Cao R, Hosaka K, Cao Y (2012) PDGF-BB modulates hematopoiesis and tumor angiogenesis by inducing erythropoietin production in stromal cells. Nat Med 18(1):100-110

Yeh CN, Maitra A, Lee KF, Jan YY, Chen MF (2004) Thioacetamideinduced intestinal-type cholangiocarcinoma in rat: an animal model recapitulating the multi-stage progression of human cholangiocarcinoma. Carcinogenesis 25(4):631-636 